\title{
GÊNERO E SEXUALIDADE NA EDUCAÇ̃̃O FíSICA ESCOLAR: UM BALANÇO DA PRODUÇÃO DE ARTIGOS CIENTÍFICOS NO PERÍODO DE 2004 A 2014 NAS BASES DO LILACS E SCIELO
}

\author{
Glenda Macedônia Gutierres Sabatel \\ Universidade Estadual Paulista, Presidente Prudente, São Paulo, Brasil \\ Stephanie de Sousa Alves \\ Universidade Estadual Paulista, Presidente Prudente, São Paulo, Brasil \\ Marcos Vinicius Francisco \\ Universidade do Oeste Paulista, Presidente Prudente, São Paulo, Brasil \\ Márcia Regina Canhoto de Lima \\ Universidade Estadual Paulista, Presidente Prudente, São Paulo, Brasil
}

\begin{abstract}
Resumo
Por meio da revisão de literatura, analisaram-se as principais características presentes nos artigos científicos sobre gênero e sexualidade na Educação Física Escolar publicados no Brasil nas bases de dados do Lilacs e Scielo. Procedeu-se pelo levantamento de artigos produzidos entre 2004-2014. Os resultados apontam que, mesmo evidenciando diferentes referenciais teórico-epistemológicos, os artigos, em sua totalidade, apresentam concepções sobre gênero e sexualidade que rompem com visões naturalizantes ou biologicistas. Eles conferem ênfase ao processo histórico, social e cultural de construção de gênero e sexualidade. Contudo, a temática de gênero tem mais visibilidade nessas produções, enquanto que a de sexualidade, em vários artigos, recebe apenas o papel de coadjuvante.
\end{abstract}

Palavras-chave: Gênero; Sexualidade; Educação Física escolar.

\section{Introdução}

Mesmo diante de avanços alcançados, em especial, por meio dos debates acadêmicos e científicos produzidos no Brasil, a partir dos anos finais da década de 1980 e início de 1990, os temas de gênero e sexualidade requerem ainda, maior visibilidade no ambiente escolar e acadêmico. $\mathrm{O}$ aumento de estudos e pesquisas pode ampliar as possibilidades da formação inicial das(os) futuras(os) professoras(es) e sua posterior atuação profissional, ao oportunizar uma compreensão mais ampla das referidas temáticas. A Educação Física Escolar coloca-se como um espaço que pode contribuir de maneira efetiva ao debate.

Contudo, trabalhar gênero e sexualidade na Educação Física Escolar requer progressos, principalmente na formação inicial dos futuros docentes, a fim de que superem em suas aulas, argumentos sexistas de caráter biológico que se encontram embutidos em uma cultura machista e preconceituosa, na qual a superioridade masculina é tida como padrão-

\footnotetext{
${ }^{1}$ Este projeto é decorrente de ações que contaram com o financiamento do Programa Institucional de Bolsa de Iniciação à Docência (Pibid) e Bolsa da Pró-Reitoria de Extensão da Universidade Estadual Paulista (PROEX/UNESP).
} 
referência (ALTMANN; AYOUB; AMARAL, 2011; ALTMANN; MARIANO; UCHOGA, 2012; CRUZ; PALMEIRA, 2009; PRADO, 2014). Atrelado a isso, as dificuldades de discussão sobre a temática estão pautadas na confusão de seus conceitos, ao difundir a ideia de que gênero está relacionado apenas às características de feminino e masculino (lógica binária), e a sexualidade, às identidades sexuais (CRUZ; PALMEIRA, 2009; PRADO; RIBEIRO, 2010).

Em contraponto a essa realidade que tem caracterizado a Educação Física Escolar, cresce o número de programas de Pós-Graduação Stricto Sensu ${ }^{2}$ e o número autores(as) da área que apresentam estudos para enriquecer o conhecimento a respeito dos temas de gênero e sexualidade. São pesquisas que relatam experiências e resultados na área de Educação Física Escolar ou que têm como objetivo nortear e ajudar as(os) docentes a construir novas possibilidades de diálogo (ALTMANN; AYOUB; AMARAL, 2011; ALTMANN; MARIANO; UCHOGA, 2012; CARDOSO; FELIPE; HEDEGAARD, 2005; KLEINUBING; SARAIVA; FRANCISCHI, 2013).

Os seguintes questionamentos perpassam o texto: de que maneira as discussões a respeito de gênero e sexualidade estão sendo interpretadas/ressiginificadas pela área de Educação Física Escolar? Por que os temas de gênero e sexualidade ainda são pouco abordados frente ao referido componente curricular?

Na primeira parte do artigo delineou-se o percurso metodológico, a fim de oferecer um panorama acerca das produções de artigos científicos no Brasil que tenham como interface a Educação Física escolar e as questões de gênero e sexualidade no período que compreende 2004-2014 nas bases do Lilacs e do Scielo. Posteriormente, apresentam-se discussões sobre como a Educação Física escolar vem compreendendo e visibilizando as questões de gênero e as diversas formas de sexualidade.

\section{Método}

O presente estudo é uma revisão de literatura. Segundo Bento (2012), esse método oferece oportunidades para orientar e avaliar o conhecimento produzido em pesquisas sobre determinado tema, a fim de se obter um panorama do nível de discussões efetuadas até então.

Foram utilizados artigos publicados em revistas indexadas nas bases de dados do Lilacs e do Scielo. A seleção da base do Scielo se deu em decorrência da disponibilização em acesso aberto, online, de textos completos publicados em periódicos brasileiros de diferentes áreas do conhecimento, avaliados por seu mérito científico, formato e endogenia, qualidade do conselho editorial e revisores, caráter científico e qualidade dos artigos, processo de arbitragem por pares, além de sua importância para o desenvolvimento do conhecimento. Vários periódicos com os extratos mais elevados no qualis das áreas de Educação e Educação Física no Brasil encontram-se indexados na referida base. A seleção do Lilacs se deu diante da contemplação dos critérios supracitados, consoante ao fato de ser uma base de dados reconhecida internacionalmente com revistas indexadas pela área de Ciências da Saúde, na qual a Educação Física se encontra vinculada junto a CAPES (Coordenação de Aperfeiçoamento de Pessoal de Nível Superior). Entende-se que tais bases poderiam

\footnotetext{
${ }^{2}$ Os seguintes Programas de Pós-Graduação da área de Educação Física apresentam pesquisadores estudando os temas de gênero e/ou sexualidade: Universidade Católica de Brasília (UCB), Universidade de Brasília (UNB), Universidade do Estado de Santa Catarina (UDESC), Universidade Estadual de Campinas (UNICAMP), Universidade Federal de Viçosa (UVF)/Universidade Federal de Juiz de Fora (UFJF), Universidade Federal do Rio Grande do Norte (UFRN), Universidade Federal do Rio Grande do Sul (UFRGS) e Universidade Federal de Santa Catarina (UFSC).
} 
favorecer uma vasta busca de artigos que abrangessem as discussões assumidas nessa investigação.

Buscou-se verificar a produção acadêmica sobre gênero e sexualidade na Educação Física Escolar, tendo como referência que essa articulação abrange elementos ligados à organização do trabalho pedagógico, como por exemplo, o currículo, as aulas, os temas e conteúdos, a prática pedagógica e a estrutura física da escola. Além disso, procedeu-se ao levantamento dos referenciais epistemológicos que subsidiaram as discussões dos artigos, com a intenção de analisar as discussões empreendidas.

Os descritores iniciais utilizados para o levantamento dos artigos foram "gênero", "sexualidade" e "Educação Física". Devido ao fato de conter uma quantidade significativa de artigos não relevantes para a pesquisa, mesmo ao delimitar o recorte de uma década, optou-se por utilizar os operadores boleanos " $e$ " e "and" para atingir melhor eficiência e qualidade no processo de identificação dos artigos. Os cruzamentos realizados foram "gênero eland sexualidade", "gênero e/and Educação Física" e "Gênero eland sexualidade e/and Educação Física".

Em ambas as bases adotaram-se alguns filtros na pesquisa: 1- os descritores mencionados acima deveriam aparecer nos textos; 2- os periódicos nos quais os artigos estavam publicados deveriam ser do Brasil; 3- delimitou-se a temporalidade 2004-2014.

Na sequência, procedeu-se pela leitura de todos os resumos dos artigos para verificar se eles propunham discussões que abrangessem os temas de gênero e sexualidade na Educação Física Escolar. Os artigos foram lidos na íntegra e fichados com a intenção de extrair os conceitos e as ideias centrais. O quadro a seguir apresenta os artigos selecionados ${ }^{3}$.

\section{Quadro 1 - Quadro-síntese do processo inicial de busca de artigos}

\begin{tabular}{|l|c|c|c|c|}
\hline \multicolumn{1}{|c|}{ Descritores } & $\begin{array}{c}\text { Total de } \\
\text { artigos na } \\
\text { Base Scielo }\end{array}$ & $\begin{array}{c}\text { Artigos } \\
\text { selecionados } \\
\text { na Base } \\
\text { Scielo }\end{array}$ & $\begin{array}{c}\text { Total de } \\
\text { artigos na } \\
\text { Base } \\
\text { Lilacs }\end{array}$ & $\begin{array}{c}\text { Artigos } \\
\text { selecionados } \\
\text { na Base } \\
\text { Lilacs }\end{array}$ \\
\hline $\begin{array}{l}\text { "Gênero eland } \\
\text { Educação Física" }\end{array}$ & 30 & 10 & 30 & 07 \\
\hline $\begin{array}{l}\text { "Gênero e/and } \\
\text { Sexualidade" e/and } \\
\text { "Gênero } \\
\begin{array}{l}\text { Sexualidade } \\
\text { Educação Física" }\end{array}\end{array}$ & 01 & 03 & 210 & 02 \\
\hline \multicolumn{1}{|c|}{ TOTAL } & 239 & 14 & 01 & 01 \\
\hline
\end{tabular}

Fonte: Pesquisa bibliográfica, 2014.

Na base Scielo, dos 30 artigos encontrados com o cruzamento "gênero and Educação Física", dez deles foram selecionados por contemplarem os temas de gênero e sexualidade em relação à Educação Física na educação básica. Os demais artigos foram excluídos por apresentarem discussões de gênero em outros espaços além da esfera escolar.

Dos 208 artigos encontrados com os descritores "Gênero and Sexualidade", somente três foram selecionados, sendo que um deles também apareceu nos demais cruzamentos.

\footnotetext{
${ }^{3}$ Com a intenção de garantir consistência à discussão apresentada neste artigo, procedeu-se pela inserção de outras bibliografias, para além das encontradas no processo de busca nas bases do Lilacs e Scielo.
} 
Entre os artigos não selecionados, a maioria abordava o tema da sexualidade a partir dos seguintes temas: o uso de métodos contraceptivos, doenças, sexualidade na adolescência, reprodução, políticas de gênero e análise de obras literárias.

Com relação à base Lilacs, dos 210 artigos encontrados com o cruzamento "Gênero and Sexualidade", apenas dois contemplavam o tema estudado. Os demais foram descartados diante do fato de abordarem discussões como: reprodução, gravidez na adolescência, iniciação sexual, DSTs, métodos contraceptivos, políticas de gênero e programas sociais. No que se refere aos descritores "Gênero e/and Sexualidade e/and Educação Física" foi encontrado e selecionado apenas um artigo.

Pesquisando com os descritores "Gênero and Educação Física" foram encontrados 30 artigos, dos quais sete foram selecionados. Desses artigos, três deles já haviam sido identificados na base de dados Scielo e um foi encontrado nos cruzamentos "Gênero and Sexualidade" e "Gênero and Sexualidade and Educação Física" na própria base do Lilacs.

É importante salientar que o número de 24 artigos selecionados em ambas as bases deve ser entendido como o número total de artigos que se atendiam os propósitos desta investigação. Todavia, muitos deles eram repetidos, apareceram tanto na base do Lilacs como na do Scielo, ou foram contemplados em mais de um dos cruzamentos. Apresentam-se abaixo (Quadro 02), os artigos selecionados.

\section{Quadro 02 - Artigos da revisão de literatura pesquisados nas bases Lilacs e Scielo}

\begin{tabular}{|c|c|c|c|}
\hline Artigo/Autores & Revista & Publicação & $\begin{array}{c}\text { Base } \\
\text { indexada }\end{array}$ \\
\hline $\begin{array}{l}\text { Divergências de gênero em turmas de } \\
\text { Educação Física - CARDOSO, F.L.; } \\
\text { FELIPE, M.L.; HEDEGAARD, C. }\end{array}$ & $\begin{array}{l}\text { Psicologia: } \\
\text { Teoria e } \\
\text { Pesquisa }\end{array}$ & 2005 & Scielo \\
\hline $\begin{array}{l}\text { Construção da identidade de gênero } \\
\text { na educação física escolar - CRUZ, } \\
\text { M.M.S; PALMEIRA, F.C.C. }\end{array}$ & Motriz $^{4}$ & 2009 & Lilacs \\
\hline $\begin{array}{l}\text { Gênero, sexualidade e educação } \\
\text { física escolar: um início de conversa } \\
\text { - PRADO, V.M.; RIBEIRO, A.I.M. }\end{array}$ & Motriz & 2010 & Lilacs \\
\hline $\begin{array}{l}\text { Indícios de sentidos e significados de } \\
\text { feminilidade e masculinidade em } \\
\text { aulas de educação física - SANTOS, } \\
\text { V.C. }\end{array}$ & Motriz & 2010 & $\begin{array}{l}\text { Scielo e } \\
\text { Lilacs }\end{array}$ \\
\hline $\begin{array}{l}\text { Escola de formação de "professoras": } \\
\text { as relações de gênero no currículo } \\
\text { superior da educação física - } \\
\text { SILVEIRA, V.T.; RIGO, L.C.; } \\
\text { CÉSAR, M.R.A.; PARDO, E.R. }\end{array}$ & $\begin{array}{l}\text { Revista } \\
\text { Brasileira de } \\
\text { Ciências do } \\
\text { Esporte }\end{array}$ & 2011 & Scielo \\
\hline \begin{tabular}{lll}
\multicolumn{3}{l}{ Estudos de gênero na educação física } \\
brasileira $\quad-\quad$ DEVIDE, & F.P.; \\
OSBORNE, R.; SILVA, & E.R.; \\
FERREIRA, R.C.; & CLAIR, & E.S.; \\
NERE, L.C.P. & & \\
\end{tabular} & Motriz & 2011 & $\begin{array}{c}\text { Scielo e } \\
\text { Lilacs }\end{array}$ \\
\hline Gênero na prática docente em & Estudos & 2011 & Scielo \\
\hline
\end{tabular}

\footnotetext{
${ }^{4}$ A Revista Motriz foi admitida na base Scielo apenas no ano de 2011, dessa forma o número mais antigo e disponibilizado é o número 3 do ano de 2010.
} 


\begin{tabular}{|c|c|c|c|}
\hline $\begin{array}{lrrr}\text { educação física: } & \text { "meninas } & \text { não } \\
\text { gostam de } & \text { suar e } & \text { meninos } & \text { são } \\
\text { habilidosos } & \text { ao } & \text { jogar?" } & - \\
\text { ALTMANN, H.; } & \text { AYOUB, } & \text { E.; } \\
\text { AMARAL, S.C.F. } & & \end{array}$ & Feministas & & \\
\hline $\begin{array}{l}\text { Gênero, corpo e sexualidade } \\
\text { negociações nas brincadeiras do } \\
\text { pátio escolar - WENETZ, I. }\end{array}$ & $\begin{array}{c}\text { Cadernos } \\
\text { CEDES }\end{array}$ & 2012 & Scielo \\
\hline $\begin{array}{l}\text { Gênero e culturas infantis: os } \\
\text { clubinhos da escola e trocinhas do } \\
\text { Bom Retiro }- \text { Cruz, T.M. }\end{array}$ & $\begin{array}{c}\text { Educação e } \\
\text { Pesquisa }\end{array}$ & 2012 & Scielo \\
\hline $\begin{array}{l}\text { Do corpo que distingue meninos e } \\
\text { meninas na educação física escolar - } \\
\text { DORNELLES, P.G. }\end{array}$ & $\begin{array}{c}\text { Cadernos } \\
\text { CEDES }\end{array}$ & 2012 & $\begin{array}{c}\text { Scielo e } \\
\text { Lilacs }\end{array}$ \\
\hline $\begin{array}{l}\text { Corpo e movimento produzindo } \\
\text { diferenças de gênero na educação } \\
\text { infantil }- \text { ALTMANN, H.; } \\
\text { MARIANO, M.; UCHOGA, L.A.R. }\end{array}$ & $\begin{array}{c}\text { Pensar a } \\
\text { Prática }\end{array}$ & 2012 & Lilacs \\
\hline $\begin{array}{l}\text { As (des)construções de gênero e } \\
\text { sexualidade no recreio escolar - } \\
\text { WENETZ, I.; STIGGER, M.P.; } \\
\text { MEYER, D.E. }\end{array}$ & $\begin{array}{l}\text { Revista } \\
\text { Brasileira de } \\
\text { Educação } \\
\text { Física e } \\
\text { Esporte }\end{array}$ & 2013 & $\begin{array}{c}\text { Scielo e } \\
\text { Lilacs }\end{array}$ \\
\hline $\begin{array}{l}\text { A dança no ensino médio: reflexões } \\
\text { sobre estereótipos de gênero e } \\
\text { movimento - KLEINUBING, N.D.; } \\
\text { SARAIVA, M.C.; FRANCISCHI, } \\
\text { V.G. }\end{array}$ & $\begin{array}{c}\text { Revista de } \\
\text { Educação } \\
\text { Física/UEM }\end{array}$ & 2013 & Scielo \\
\hline $\begin{array}{l}\text { Gender equity in physical education: } \\
\text { the use of language - } \\
\text { ANDRÉS,O.D.C; GRANADOS,S.R; } \\
\text { RAMIIREZ,T.G; MESA,M.D.C.D. }\end{array}$ & Motriz & 2014 & $\begin{array}{c}\text { Scielo e } \\
\text { Lilacs }\end{array}$ \\
\hline $\begin{array}{l}\text { "Prendam suas bezerras que meu } \\
\text { garrote está solto!" interseccionando } \\
\text { gênero, sexualidade e lugar nos } \\
\text { modos de subjetivação regionais - } \\
\text { DORNELLES, P.G.; POCAHY, F.A. }\end{array}$ & $\begin{array}{c}\text { Educar em } \\
\text { Revista }\end{array}$ & 2014 & Scielo \\
\hline
\end{tabular}

Fonte: Pesquisa bibliográfica, 2014.

\section{A visibilidade dos temas Gênero e Sexualidade nas discussões em Educação Física Escolar}

Gênero e sexualidade são temas que vêm adquirindo maior visibilidade, se comparado há alguns anos atrás (CRUZ, 2012). No entanto, mesmo diante de uma considerável gama de artigos encontrados em bases de pesquisas, poucos são os estudos que interseccionam discussões com a área da Educação Física Escolar. Dos artigos selecionados nesta pesquisa, nas bases do Lilacs e Scielo, apenas 12 deles contemplam tais discussões. Os outros três artigos abordam essas temáticas em consonância com o meio escolar, de maneira ampla, todavia trazem à tona assuntos que são trabalhados no componente curricular de Educação Física. 
As discussões em relação à temática de gênero no Brasil tiveram início em decorrência da lacuna histórica e cultural existente entre os sexos, por meio da qual a mulher era inferiorizada em relação à figura do homem. A partir de 1930 houve maior abertura para a educação feminina, todavia numa perspectiva dual de ensino, com claras especializações para o gênero. As questões de gênero, a partir desse contexto, por intermédio dos movimentos feministas, ganharam visibilidade na luta pela igualdade da mulher. Até então, gênero era utilizado apenas para conceituar as diferenças de sexo (CRUZ; PALMEIRA, 2009).

De acordo com Silva (2003), a palavra gênero foi utilizada pela primeira vez com uma nova concepção, apenas em 1955, pelo biólogo norteamericano John Money, ao enfatizar a necessidade de se contemplar em sua definição os aspectos sociais do sexo. No Brasil, apenas nos anos finais da década de 1980 e início de 1990 que a temática tornou-se importante na academia, em especial, na área educacional (DINIS, 2008).

Conforme Louro (1997, p.28), compreende-se gênero como a construção identitária dos indivíduos, num processo contínuo, situado socialmente e historicamente. "Em suas relações sociais, os indivíduos vão se construindo como masculinos ou femininos, arranjando e desarranjando seus lugares sociais [...]".

Para Scott (1995, p.86), a conceituação de gênero abrange dois aspectos: "o gênero é um elemento constitutivo de relações sociais baseadas nas diferenças percebidas entre os sexos, e gênero é uma forma primária de dar significado às relações de poder".

Frente a essas ponderações, ao entender o gênero como uma construção social e histórica das diferenças entre os sexos, tem-se que a feminilidade e a masculinidade não se constituem, em específico, pelas características biológicas (DORNELLES, 2012; PRADO; RIBEIRO, 2010; SANTOS, 2010). Santos (2010, p.842) define a feminilidade e a masculinidade como "construções culturais que se produzem e reproduzem socialmente e que não podem ser definidas fora de um contexto, ou seja, de condições históricas e culturais em que o indivíduo se constitui".

A partir de Louro (1997), na busca por uma definição de sexualidade, tem-se que as identidades sexuais são constituídas por intermédio das mais diversificadas formas pelas quais os indivíduos vivem sua sexualidade. A identidade sexual deve ser entendida como um constructo instável e mutável, em constante estado de transformação (SANTOS, 2010).

Prado e Ribeiro (2010, p.409) ponderam que, habitualmente, quando se fala em orientação sexual ou sexo biológico, as pessoas concebem que se está falando exclusivamente sobre sexualidade. Diante disso, argumentam que "embora o sexo biológico e a orientação sexual estejam relacionados com a sexualidade humana, esta não se resume simplesmente ao biológico ou a orientação do desejo". Embora nem todos os trabalhos mencionem o seu enfoque teórico-epistemológico, seis deles apresentam suas discussões a partir dos estudos culturais, feministas e de gênero com destaque para as interlocuções com as obras de Judith Butler, Guacira Louro e Joan Scott, na vertente pós-estruturalista de Foucault (DORNELLES, 2012; DORNELLES; POCAHY, 2014; PRADO; RIBEIRO, 2010; SILVEIRA et al., 2011; WENETZ, 2012; WENETZ; STIGGER; MEYER, 2013); três deles assentam-se nos estudos de gênero e nos estudos antropológicos baseados em pressupostos de Geertz (CARDOSO; FELIPE; HEDEGAARD, 2005; ALTMANN; AYOUB; AMARAL, 2011; ALTMANN; MARIANO; UCHOGA, 2012); um apresenta discussões dos estudos de gênero em consonância com a perspectiva histórico-cultural de Vigotski e a concepção enunciativodiscursiva de Bakhtin, autores cuja base epistemológica é o marxismo (SANTOS, 2010); um apresenta uma intersecção entre os estudos de gênero e a sociologia da infância, com destaque para as obras de Florestan Fernandes (CRUZ, 2012); um discute seus dados a partir dos estudos de gênero numa inclinação fenomenológica hermenêutica em diálogo com a obra de Fini (KLEINUBING; SARAIVA; FRANCISCHI, 2013). Por fim, os estudos de Cruz e Palmeira (2009); Devide et al. (2011) e Andrés et al., (2014) não mencionam seu enfoque 
teórico-epistemológico, mas ao proceder pela leitura dessas obras, ficou evidente que as duas primeiras pautam-se a partir dos estudos feministas e de gênero, enquanto que a última, oriunda de um grupo de pesquisadores espanhóis, fundamenta-se em autores internacionais sem muita visibilidade no Brasil.

Em pesquisa que visou mapear as correntes teóricas dos estudos de gênero da Educação Física brasileira em teses, dissertações e livros, Devide et al. (2011) constataram que a maioria dessas obras (com início nos anos de 1980, ganharam expressão na década seguinte) foram organizadas em três linhas: marxista, culturalista e pós-estruturalista, com predominância das duas últimas em articulação com os estudos feministas e de gênero. $\mathrm{Na}$ presente investigação, ao se olhar para a produção de artigos científicos em periódicos qualificados nas bases supracitadas, constatou-se uma maior consolidação da vertente pósestruturalista, em articulação com os estudos de gênero e sexualidade.

Outro ponto a considerar diz respeito à compreensão de gênero entre os artigos investigados. Nicholson (2000, p.09) esclarece que gênero vem sendo utilizado de duas maneiras contraditórias. Há os que usam gênero adversamente a sexo, na expectativa de descreverem o que é socialmente construído, em oposição ao que é biologicamente dado. Gênero e sexo nessa perspectiva são tidos como distintos. Em oposição, de forma crescente, o uso do constructo gênero é tido "como referência a qualquer construção social que tenha a ver com a distinção masculino/feminino, incluindo as construções que separam corpos "femininos" de corpos "masculinos"'. Essa forma passou a ser usada, sobretudo, porque se entende que a sociedade não forma apenas a personalidade e o comportamento, mas também as maneiras como o corpo ganha destaque. Nessa lógica, se o próprio corpo é sempre visto como algo passível de ser interpretado socialmente, por conseguinte, o sexo não pode ser independente do gênero. Dos artigos aqui analisados, um deles apresenta associação com a primeira forma de uso do termo gênero (SILVEIRA et al., 2011). Enquanto que as demais pesquisas, para além das diferenças epistemológicas já mencionadas, conferem ênfase a aspectos que expressam afinidade com a segunda forma de compreensão de gênero.

Há que se registrar ainda que a temática de gênero foi mais visibilizada nos artigos analisados, enquanto que a temática de sexualidade, em várias investigações, recebeu papel secundário, ao não ser conceituada e/ou tida apenas como um complemento do que vem a ser gênero. Entende-se que essa vinculação seja primordial, ao passo que de acordo com Prado (2014):

\footnotetext{
No que se refere à identificação do sujeito com a vivência dos prazeres, alguns marcadores específicos delimitam as possibilidades (e limites) para essas relações. Os marcadores sociais de gênero e sexualidade, por exemplo, se configuram enquanto dispositivos que, em muitos casos, estabelecem a subjugação e a falta de legitimidade para múltiplos modos de existência. Ser enquadrado enquanto homem ou mulher, masculino ou feminino e ser forçado a desenvolver determinadas práticas ditas "sexuais" são estratégias políticas que posicionam os corpos/subjetividades a partir de um ideal de normalização focado na noção de uma heterossexualidade natural, universal e homogeneizada (PRADO, 2014, p.20).
}

É fato que outros marcadores também exercerão influências no processo de construção identitária dos sujeitos, tais como os dispositivos "acionados pelas noções de diferença sexual, raça, etnia, categoria geracional, deficiência, religião, nacionalidade, regionalidade e classe social" (PRADO, 2014, p.20). Todavia, não se pode perder de vista que os marcadores de gênero e sexualidade precisam ser visibilizados, complementando-se um ao outro, salvo suas especificidades conceituais, como já destacado, tendo em vista que discursos hegemônicos, socialmente construídos contribuem para que algumas pessoas sofram diversas formas de violência e de privação de seus prazeres. Ainda, ao se referir à sexualidade, o autor 
complementa que o discurso pedagógico, comumente omisso frente à temática e distante da ótica heterossexual, não promove questionamentos sobre essas aparentes diferenças.

Com relação às tipologias de pesquisas, os artigos selecionados seguiram os propósitos da pesquisa qualitativa, bibliográfica, documental e do tipo etnográfica. No que tange aos procedimentos metodológicos, em linhas gerais adotaram: análise documental, aplicação de questionários, observação, história oral, observação participante, diários de campo e grupo focal.

Há que se ressaltar que no recorte temporal entre 2004-2014, a primeira publicação encontrada tem data de 2005, fruto da parceria de pesquisadores brasileiros com um francês, referência internacional no tema. A partir de então, apenas em 2009, os temas de gênero e sexualidade nas aulas de Educação Física Escolar voltaram a ter espaço em uma revista brasileira. Posteriormente, houve maior regularidade de publicações, com destaque para o ano de 2012.

Além disso, os autores desses artigos são provenientes de universidades localizadas exclusivamente nas regiões sul, sudeste e nordeste do país, o que evidencia certo descompasso nessas produções e o quanto o tema precisa de maior visibilidade. Os investigadores e os artigos produzidos estão vinculados a grupos de pesquisas da Universidade Federal de Pelotas (UFPel), Universidade Federal do Rio Grande do Sul (UFRGS), Universidade do Estado de Santa Catarina (UDESC), Universidade do Sul de Santa Catarina (UNISUL), Universidade Comunitária da Região de Chapecó (Unochapecó), Universidade Federal do Paraná (UFPR), Universidade Estadual Paulista - campus de Presidente Prudente-SP (FCT/UNESP), Universidade Estadual de Campinas (UNICAMP), Universidade Metodista de Piracicaba (UNIMEP), Universidade Salgado de Oliveira Niterói-RJ (UNIVERSO), Universidade do Estado da Bahia (UNEB), Universidade Federal da Bahia (UFBA), Universidade Federal do Recôncavo da Bahia (UFRB) e Universidade de Fortaleza (UNIFOR).

A partir dessa constatação, três aspectos merecem destaque. O primeiro refere-se ao fato de que a maioria desses artigos provém de instituições das regiões sul e sudeste, onde há uma elevada concentração dos Programas de Pós-Graduação em Educação Física (PPGEF). Poucos são os programas localizados nas regiões Centro-Oeste e Nordeste do país; na região Norte sua presença ainda é inexistente. Segundo, ao consultar onde as(os) pesquisadoras(es) realizaram seus mestrados/doutorados em Programas da área de Educação Física, foi confirmado que aquelas(es) que estão inseridas(os) em universidades da região nordeste, em sua maioria, alcançaram tais níveis de titulação em universidades do sul e sudeste. Por fim, ao mencionar a produção sobre gênero e sexualidade em articulação com a Educação Física Escolar, não se pode desmerecer os programas da área de Educação, Psicologia e Ciências Sociais, por exemplo, que absorveram muitas(os) estudantes oriundas(os) das áreas de Educação Física. A área possui 29 programas no Brasil, sendo escassos os programas que contemplam discussões de cunho pedagógico ou que abordam a Educação Física Escolar.

\section{Mas por que os temas de gênero e sexualidade precisam ser abordados de forma crítica na Educação Física Escolar?}

Os temas de gênero e sexualidade são importantes e necessários para o trabalho dentro das escolas, em especial, na Educação Física (ALTMANN; MARIANO; UCHOGA, 2012; PRADO; RIBEIRO, 2010). Almeja-se que, por seu intermédio, (as)os estudantes possam perceber que seus valores, discursos e posturas são social e culturalmente construídos. As aulas de Educação Física podem ser um importante espaço para auxiliar na desconstrução de estereótipos ou práticas que favorecem a segregação de meninos e meninas, ocasionando desigualdades de gênero e sexualidades (ALTMANN; AYOUB; AMARAL, 2011; 
ALTMANN; MARIANO; UCHOGA, 2012; PRADO, 2014; PRADO; RIBEIRO, 2010; SANTOS, 2010).

Todavia, infere-se que a polarização da produção em poucas universidades, no Brasil, como destacado acima, faz com que as contribuições produzidas por intermédio de pesquisas não sejam inseridas de forma suficiente no processo de formação inicial das(os) professoras(es) de Educação Física. Nessa dinâmica imperam ainda práticas e discursos advindos do senso comum que dificultam uma abertura aos temas de gênero e sexualidade na práxis pedagógica em Educação Física.

Altmann, Ayoub e Amaral (2011) em uma investigação constataram que metade das(os) professoras(es) não se atentavam às questões de gênero no momento do planejamento anual das aulas. Muitos professores defendiam a segregação por gênero nas aulas, ao reforçarem discursos que evidenciavam expectativas distintas em torno do resultado de suas ações. Tais dados corroboram com os achados de Cruz e Palmeira (2009), pois, por mais que as(os) professoras(es) de sua pesquisa considerassem importante a co-educação ${ }^{5}$, eles ainda empregavam discursos sexistas que deixavam transparecer preconceitos de gênero.

$\mathrm{Na}$ concepção de muitas(os) professoras(es), a segregação melhora a qualidade e aproveitamentos das aulas de Educação Física, já que culturalmente os meninos são tidos como mais habilidosos e fortes nas práticas esportivas e jogos coletivos. As meninas, por sua vez, são consideradas mais frágeis, além de não gostarem de suar ou realizar exercícios que exijam maior esforço físico (ALTMANN; AYOUB; AMARAL, 2011; ALTMANN; MARIANO; UCHOGA, 2012; DORNELLES, 2012; SANTOS, 2010).

Não se pode esquecer que "a lógica que se estabelece é a do masculino como regra, norma, padrão, ou seja, como representação ideal de aluno nessa disciplina" (DORNELLES, 2012, p.195). Esse tipo de prática coloca em evidência as normas de gênero. Aliás, essa é uma forma de se educar para a sexualidade, a partir de padrões heteronormativos.

Braga (2014) destaca que a heteronormatividade se converte na base de todo um sistema político-subjetivo que, ao tomar a heterossexualidade como obrigatória, norma e padrão, determina a impossibilidade de vida fora de suas balizas. Por seu intermédio, produzse e alimenta a diferença dicotômica entre os sexos; criam-se as regras de inteligibilidade de gênero, que para um corpo ter "coerência", deverão respeitar a ordem compulsória sexo/gênero/desejo. Nessa ótica, o masculino, o homem passa a ser tido como universal (BRAGA, 2014; CAETANO, 2011; PRADO, 2014).

Como exemplo de produção da heteronormatividade, pode-se mencionar a homofobia, entendida como "uma forma tanto de evidenciar a linha que separa os que estão mais articulados à norma dos que se distanciam dela, produzindo tanto sujeitos normais e "anormais", quanto de garantir a superioridade heterossexual" (BRAGA, 2014, p.107). Para Braga (2014), faz-se imperioso desconstruir todos os discursos e práticas que tomam a heterossexualidade como obrigatória.

Cruz e Palmeira (2009) apontam que além da escola, a família, historicamente, teve/tem papel direto na construção/difusão de conceitos e valores que perpetuam na atualidade. Muitas vezes, esses valores restringem as atividades e vivências das mulheres, ao se naturalizar culturalmente a soberania dos homens.

Kleinubing, Saraiva e Francischi (2013) observam que antigamente as diferenciações que ocorriam no que se delimita enquanto papéis sociais estavam engendradas no sexo biológico, na anatomia e na fisiologia dos corpos. Com o passar do tempo, essa lógica ajudou a construir e reforçar a superioridade do sexo masculino dentro da sociedade, diferenciando o

\footnotetext{
${ }^{5}$ É importante ressaltar que as aulas coeducativas ultrapassam o formato de aulas mistas (meninas e meninos), ou seja, são planejadas com a intenção de se abordar e problematizar por meio das vivências e diferentes atividades os temas de gênero e sexualidade (CRUZ; PALMEIRA, 2009).
} 
que deveria se esperar do homem e da mulher. Partindo desse pressuposto, as autoras utilizaram-se do conteúdo de dança, no Ensino Médio, para evidenciar como alguns estereótipos dificultam o desenvolvimento das aulas de Educação Física, tais como, que "dança é coisa de menina", de que "toda menina gosta de dança" ou que "todo menino gosta de esporte". Contudo, em função das oportunidades de vivência e reflexão crítica sobre a dança, as(os) estudantes, no plano discursivo, transgrediram alguns destes estereótipos.

Sobre o posicionamento das(os) docentes que defendem a segregação por gênero nas aulas de Educação Física, é necessário ponderar que esse tipo de argumento não foi produzido ao acaso. Ele é reflexo também, do processo histórico de formação dos professores da área no Brasil.

Silveira et al. (2011) relataram que ao analisarem as práticas curriculares que atuaram na formação das professoras de Educação Física da Escola de Educação Física da Universidade Federal de Pelotas (ESEF/ UFPel), nas décadas de 1970 e 1980, constataram que elas eram construídas a partir de uma concepção biologizante que maximizava as diferenças entre homens e mulheres. Havia também a segregação por gênero na constituição do próprio corpo docente e disciplinas específicas para homens e mulheres.

Sobre a prática de segregação por gêneros, Santos (2010, p.851) pondera que "a linguagem, que atravessa e constitui a maioria das práticas, não apenas expressa relações, poderes, ela os institui. Ela não apenas veicula, mas produz e tenta fixar diferenças entre os sujeitos".

Ainda sobre os discursos presentes na fala de muitas(os) professoras(es), como justificativas para a separação por gênero, Altmann, Mariano e Uchoga (2012) ponderam que as(os) docentes necessitam compreender que meninos e meninas apresentam maneiras distintas de se comportarem e agirem. Quando chegam às escolas, esses meninos e meninas trazem consigo uma bagagem cultural, fruto das relações construídas no seu dia a dia.

De acordo com Wenetz (2012) e Wenetz et. al (2013), o gênero se amplia para além dos papeis sociais, ao se tornar uma construção social, por meio da qual a escola deve atuar intencionalmente. As escolas precisam coibir a separação por gênero das turmas, avançando na compreensão de que as questões de gênero e sexualidade não podem ser pautadas em parâmetros heteronormativos. Um modelo regulador social, pautado na hetenormatividade, faz com que os discursos e políticas básicas que subsidiam a Educação Física legitimem o desejo heterossexual como "normal” (DORNELLES; POCAHY, 2014).

\section{Considerações Finais}

Sem a pretensão de findar as discussões sobre o tema, buscou-se analisar como as temáticas de gênero e sexualidade vêm sendo articuladas com a Educação Física Escolar, em artigos publicados no país e disponibilizados nas bases do Lilacs e Scielo, diante do recorte temporal de uma década (2004-2014). Constatou-se que mesmo com os avanços dos estudos relacionados à área de Educação Física, sobretudo, aqueles que dialogam com os temas de gênero e sexualidade frente ao meio escolar, há ainda uma escassez de trabalhos e pesquisadoras(es) no Brasil. Eles foram produzidos por grupos de pesquisas localizados exclusivamente nas regiões Sul, Sudeste e Nordeste do país, evidenciando descompassos em sua produção, bem como que os temas precisam de maior visibilidade.

Embora apresentem diferentes referenciais teórico-epistemológicos, os artigos, em sua totalidade, evidenciam concepções sobre gênero e sexualidade que rompem com visões naturalizantes ou biologicistas. Eles dão ênfase ao processo histórico, social e cultural de construção de gênero e sexualidade. Contudo, a temática de gênero tem maior visibilidade nessas produções, enquanto que a temática de sexualidade, em vários artigos, recebeu apenas 
o papel de coadjuvante nas discussões, ao não ser conceituada e tida apenas como um complemento do que vem a ser gênero.

Assume-se a necessidade de que as discussões sobre os temas de gênero e sexualidade sejam contemplados desde o processo de formação inicial das(os) futuras(os) professoras(es) da área de Educação Física. Há que se garantir uma práxis-pedagógica que rompa com discursos sexistas advindos do senso comum, favorecedores da exclusão dos indivíduos que não se adéquam aos padrões hegemônicos, naturalizados histórica e culturalmente.

Desta forma, afirma-se quão importante e necessária é a formação de qualidade das(os) docentes, seja a inicial ou continuada, ao oferecer discussões que auxiliem na construção social e política de sujeito críticos, a ponto de romperem paradigmas cristalizados socialmente.

\title{
GENDER AND SEXUALITY IN THE SCHOLAR PHYSICAL EDUCATION: A BALANCE OF SCIENTIFIC ARTICLES PRODUCTION FROM THE PERIOD OF 2004-2014 AT THE DATABASES LILACS AND SCIELO
}

\begin{abstract}
Through literature review, we analyzed the main features found in scientific articles on gender and sexuality in the Scholar Physical Education published in Brazil at the databases Lilacs and Scielo. The survey proceeded by articles produced between 2004-2014. The results point that, even showing different theoretical and epistemological frameworks, the articles, in their entirety, present conceptions about gender and sexuality that break naturalizing or biologicist views. They give emphasis on the historical, social and cultural process of gender and sexuality construction. However, the gender issue has more visibility in these productions, while the sexuality in several articles, only received the secondary role.
\end{abstract}

Keywords: Gender; Sexuality; Scholar Physical Education.

\section{GÉNERO Y SEXUALIDAD EN LA EDUCACIÓN FÍSICA ESCOLAR: LA PRODUCCIÓN DE LOS ARTÍCULOS CIENTÍFICOS EN EL PERÍODO 2004-2014 EN LAS BASES DEL LILACS Y SCIELO}

\begin{abstract}
Resumen
A través de revisión de la literatura, se analizó las principales características presentes en los artículos científicos sobre el género y la sexualidad en la Educación Física Escolar publicados en Brasil en las bases de datos Lilacs y Scielo. Los resultados muestran que incluso mostrando diferentes marcos teóricos y epistemológicos, los artículos, en su totalidad, tienen ideas sobre el género y la sexualidad que rompen con visiones biológicas y de naturalización. Ellos dan énfasis en el proceso histórico, social y cultural de la construcción del género y la sexualidad. Sin embargo, la cuestión de género es más visualizado en estas producciones, mientras que la sexualidad en varios artículos, sólo recibió el papel secundario.
\end{abstract}

Palabras clave: Género; Sexualidad; Educación Física Escolar. 


\section{Referências}

ALTMANN, H.; AYOUB, E.; AMARAL, S.C.F. Gênero na prática docente em educação física:"meninas não gostam de suar e meninos são habilidosos ao jogar"?. Estudos feministas, Florianópolis, v.19, n.2, p.491-501, maio/ago. 2011.

ALTMANN, H.; MARIANO, M.; UCHOGA, L.A.R. Corpo e movimento produzindo diferenças de gênero na educação infantil. Pensar a Prática, Goiânia, v. 5, n. 2, p. 285-301, abr./jun. 2012.

ANDRÉS, O.D.C.; GRANADOS, S.R.; RAMÍREZ, T.G.; MESA, M.D.C.D. Gender equity in physical education: the use of language. Motriz, Rio Claro, v.20, n.3, p.239-248, jul./set. 2014.

BENTO, A.V. Como fazer uma revisão da literatura: considerações teóricas e práticas. Revista JÁ, Portugal: Associação Acadêmica da Universidade da Madeira, n. 65, ano VII, maio 2012.

BRAGA, K.D.S. Homofobia na escola: análise do livro de ocorrência escolar. 2014. 200f. Dissertação (Mestrado em Educação)-Faculdade de Ciências e Tecnologia/ Universidade Estadual Paulista, Presidente Prudente, 2014.

CAETANO, M.R.V. Gênero e sexualidade: um encontro político com as epistemologias da vida e os movimentos curriculares. 2011. 228f. Tese (Doutorado em Educação)- Universidade Federal Fluminense, Niterói, 2011.

CARDOSO, F.L.; FELIPE, M.L.; HEDEGAARD, C. Divergências de gênero em turmas de Educação Física. Psicologia: Teoria e Pesquisa, Brasília, v.21, n.3, p.349-357, set./dez. 2005.

CRUZ, T.M. Gênero e culturas infantis: os clubinhos da escola e trocinhas do Bom Retiro. Educação e Pesquisa, São Paulo, v. 38, n. 1, p. 63-78, jan./mar. 2012.

CRUZ, M.M.S.; PALMEIRA, F.C.C. Construção da identidade de gênero na educação física escolar. Motriz, Rio Claro, v.15, n.1, p.116-131, jan./mar. 2009.

DEVIDE, F.P.; OSBORNE, R.; SILVA, E.R.; FERREIRA, R.C.; CLAIR, E.S.; NERE, L.C.P. Estudos de gênero na educação física brasileira. Motriz, Rio Claro, v.17 n.1 p.93-103, jan./mar. 2011.

DINIS, N.F. Educação, relações de gênero e diversidade sexual. Educação \& Sociedade, Campinas, vol. 29, n. 103, p. 477-492, maio/ago. 2008.

DORNELLES, P.G. Do corpo que distingue meninos e meninas na educação física escolar. Cadernos Cedes, Campinas, vol. 32, n. 87, p. 187-197, maio/ago. 2012.

DORNELLES, P.G.; POCAHY, F.A. "Prendam suas bezerras que meu garrote está solto!" interseccionando gênero, sexualidade e lugar nos modos de subjetivação regionais. Educar em Revista, Curitiba, Ed. Esp., n. 1, p. 117-133, 2014. 
KLEINUBING, N.D.; SARAIVA, M.C.; FRANCISCHI, V.G. A dança no ensino médio: reflexões sobre estereótipos de gênero e movimento. Revista de Educação Física/UEM, Maringá, v. 24, n. 1, p. 71-82, jan./mar. 2013.

LOURO, G. L. Gênero, sexualidade e educação: uma perspectiva pós-estruturalista. Petrópolis, RJ: Vozes, 1997.

NICHOLSON, L. Interpretando o gênero. Revista Estudos Feministas, Florianópolis, v.8, n.2, p.9-41, jul./dez. 2000.

PRADO, V.M. Entre ditos e não ditos: a marcação social de diferenças de gênero e sexualidade por intermédio de práticas escolares da Educação Física. 2014. 258f. Tese (Doutorado em Educação)-Faculdade de Ciências e Tecnologia/ Universidade Estadual Paulista, Presidente Prudente, 2014.

PRADO, V.M.; RIBEIRO, A.I.M. Gênero, sexualidade e educação física escolar: um início de conversa. Motriz, Rio Claro, v.16, n.2, p.402-413, abr./jun. 2010.

SANTOS, V.C. Indícios de sentidos e significados de feminilidade e masculinidade em aulas de educação física. Motriz, Rio Claro, v.16, n.4, p.841-852, out./dez. 2010.

SCOTT, J. Gênero: uma categoria útil de análise histórica. Educação \& Realidade, Porto Alegre, v.20, n.2, p.71-99, jul./dez. 1995.

SILVA, T.T. As Teorias Pós Críticas. In: SILVA, T.T. Documentos de identidade: uma introdução as teorias do currículo. 2. ed. Belo Horizonte: Autêntica, 2003. p. 85-139.

SILVEIRA, V.T.; RIGO, L.C.; CÉSAR, M.R.A.; PARDO, E.R. Escola de formação de "professoras": as relações de gênero no currículo superior da educação física. Revista Brasileira de Ciências do Esporte, Florianópolis, v. 33, n. 4, p. 857-872, out./dez. 2011.

WENETZ, I. Gênero, corpo e sexualidade negociações nas brincadeiras do pátio escolar. Cadernos Cedes, Campinas, vol. 32, n. 87, p. 199-209, mai./ago. 2012.

WENETZ, I.; STIGGER, M.P.; MEYER, D.E. As (des)construções de gênero e sexualidade no recreio escolar. Revista Brasileira de Educação Física e Esporte, São Paulo, v. 27, n.1, p.117-128, jan./mar. 2013.

Recebido em: 10/03/2015

Revisado em: 08/10/2015

Aprovado em: 17/11/2015

Endereço para correspondência:

marcos_educa01@yahoo.com.br

Marcos Vinicius Francisco

Universidade do Oeste Paulista

Rodovia Raposo Tavares, Limoeiro

19060-900 - Presidente Prudente, SP - Brasil 